\title{
Cloning of the toxin gene from Pasteurella multocida and its role in atrophic rhinitis
}

\author{
Alistair J. LaX* and Neil Chanter \\ AFRC Institute for Animal Health, Compton, Newbury, Berkshire RG16 ONN, UK
}

(Received 18 July 1989; revised 31 August 1989; accepted 6 October 1989)

\begin{abstract}
The gene for the osteolytic toxin of Pasteurella multocida has been cloned into a plasmid vector and expressed off its own promoter in Escherichia coli. Particular restriction endonucleases failed to cut the gene and regions flanking it, suggesting an $A+T$ base ratio significantly greater than the remaining genome of $P$. multocida. Cloned toxin was indistinguishable from the native toxin with respect to molecular mass, antigenicity and toxicity in different tests. A single intraperitoneal injection of toxin purified from the recombinant $E$. coli reproduced in gnotobiotic pigs the pathological changes characteristic of atrophic rhinitis. The recombinant $E$. coli produced at least 10 times as much toxin as $P$. multocida.
\end{abstract}

\section{Introduction}

Atrophic rhinitis of growing pigs is characterized by atrophy of the nasal turbinate bones which, in the severest form of the disease, is complete and accompanied by the development of twisted or shortened snouts (Switzer \& Farrington, 1975). The disease is also believed to cause a reduction in weight gain (Rutter, 1985). The severe form of the disease can be detected clinically whilst less severe forms may be seen only at slaughter when turbinate bones can be inspected. Only the severe condition will be referred to as atrophic rhinitis in this paper. Attempts to reproduce atrophic rhinitis were assisted by the discovery of toxigenic isolates of Pasteurella multocida (Il'ina \& Zasukhin, 1975; De Jong et al., 1980). These were identified by the toxicity of cell free extracts for mice and guinea pigs (De Jong et al., 1980), and for cells grown in vitro (Rutter \& Luther, 1984). Inoculation of pigs with cell free extracts of toxigenic $P$. multocida either intranasally (Il'ina \& Zasukhin, 1975) or intraperitoneally (Rutter \& Mackenzie, 1984) also reproduced the disease.

The toxin from $P$. multocida, purified by several groups (Nakai et al., 1984; Chanter et al., 1986b; Rimler \& Brogden, 1986; Foged et al., 1986; Kamp et al., 1987), is a single polypeptide of molecular mass variously quoted as 112 to $160 \mathrm{kDa}$. Although purified toxin reproduced the symptoms of atrophic rhinitis (Chanter $e t$ $a l ., 1984 b$; Dominick \& Rimler, 1986) its mode of action

Abbreviation: EBL, embryonic bovine lung. is unknown. However, preliminary results suggest that it differs from other toxins (Chanter et al., 1986c). It seemed likely that analysis of the toxin at the molecular level might provide important evidence about its mechanism of action. We describe here the cloning of the toxin gene in Escherichia coli, and the properties of its product.

\section{Methods}

Strains and growth conditions. P. multocida strain LFB3 is a toxigenic isolate from a pig with atrophic rhinitis (Rutter, 1983). E. coli HB101 harbouring plasmid pAT153 was from Dr J. G. Williams, Imperial Cancer Research Fund, London, UK. All bacteria were stored as cell suspensions at $-70{ }^{\circ} \mathrm{C}$ in $12 \%(\mathrm{v} / \mathrm{v})$ giycerol. $P$. multocida were grown in Bacto-tryptose broth (Jones \& Matthews, 1975) at $37^{\circ} \mathrm{C}$ with agitation. E. coli strains were grown on LB agar or in L broth (Maniatis et al., 1982).

Chemicals and biochemicals. Restriction enzymes were from BRL or Biolabs, and were used according to the manufacturer's specifications. All other enzymes were from Boehringer. Ampicillin and tetracycline were from Sigma, and agarose from BRL. Adenosine $5^{\prime}-\alpha-\left[{ }^{35}\right]$ trithiophosphate $\left.\left({ }^{35} \mathrm{~S}\right] \mathrm{dATP}\right)$ was from Amersham. Other chemicals were from BDH.

DNA isolation and cloning techniques. P. multocida DNA was isolated by a modification of the method of Saito \& Miura (1963). Cells were collected by centrifugation and washed in an aqueous solution of $0 \cdot 15 \mathrm{M}-\mathrm{NaCl}, 0 \cdot 1 \mathrm{M}-\mathrm{EDTA}, \mathrm{pH} 8 \cdot 0$, and were resuspended in the same buffer at one-tenth the original volume of culture. Lysozyme $\left(1 \mathrm{mg} \mathrm{ml}^{-1}\right)$ was added, and the mixture was incubated at $37^{\circ} \mathrm{C}$ for $30 \mathrm{~min}$ and was then rapidly immersed in a dry ice/acetone bath. Eight volumes of lysis solution $[0.1 \mathrm{M}-\mathrm{Tris} / \mathrm{HCl}, \mathrm{pH} 9,0.1 \mathrm{M}-\mathrm{NaCl}, 1 \%(\mathrm{w} / \mathrm{v})$ SDS and $50 \mu \mathrm{g} \mathrm{ml}^{-1}$ proteinase $\left.\mathrm{K}\right]$ was added and the mixture was incubated at $60^{\circ} \mathrm{C}$ for $10 \mathrm{~min}$ before being rapidly frozen in a dry ice/acetone bath. After thawing at $60^{\circ} \mathrm{C}$ for $30 \mathrm{~min}$, an equal volume of 
phenol (Maniatis et al., 1982) was added and the suspension was mixed gently for 1-2 $\mathrm{h}$. The suspension was centrifuged and the aqueous phase was re-extracted with phenol. After phase separation, residual phenol was removed from the aqueous phase by extensive dialysis against an aqueous solution of $50 \mathrm{~mm}-\mathrm{Tris} / \mathrm{HCl}, 10 \mathrm{~mm}-\mathrm{EDTA}, 10 \mathrm{mM}^{-}$ $\mathrm{NaCl}, \mathrm{pH}$ 8. The preparation was treated with ribonuclease as described by Maniatis et al. (1982), and the purified DNA was stored at $4{ }^{\circ} \mathrm{C}$.

Genomic DNA from $P$. multocida was partially digested with SaullIA to obtain fragments of about $10 \mathrm{~kb}$. The digest was fractionated on a sucrose gradient as described by Maniatis et al. (1982). Fractions were selected containing fragments in the size range $7-12 \mathrm{~kb}$. The restricted DNA was ligated overnight at $15{ }^{\circ} \mathrm{C}$ to pAT153, previously cut with BamHI and treated with phosphatase. Competent $\mathrm{HB} 101$ cells obtained from BRL were transformed and were plated onto $\mathrm{L}$ agar containing ampicillin $\left(200 \mu \mathrm{g} \mathrm{ml}^{-1}\right)$. After incubation at $37^{\circ} \mathrm{C}$ overnight, the bacterial colonies obtained (about $6500)$ were replica-plated onto agar containing tetracycline $\left(12 \mu \mathrm{g} \mathrm{ml}^{-1}\right)$. About $2500 \mathrm{Ap}^{r} \mathrm{Tc}^{\mathrm{s}}$ colonies were tested for toxicity for embryonic bovine lung (EBL) cells by the overlay method (Chanter $e t$ $a l ., 1986 a$ ) and stored at $-70^{\circ} \mathrm{C}$ in $12 \%$ glycerol in microtitre trays.

Plasmids were isolated according to Ish-Horowitz \& Burke (1981). DNA probes were labelled by nick translation, and other molecular biological techniques were as described in Maniatis et al. (1982).

Toxin purification. A crude extract of the toxigenic recombinants TOX1 or TOX2, grown on $\mathrm{L}$ agar containing ampicillin, was produced by the lysis method of Rimler \& Brogden (1986). Crude extract, treated with RNAase, DNAase, benzamidine and phenylmethylsulphonyl fluoride was sequentially fractionated by DEAE-Sephacel chromatography and preparative PAGE (Chanter et al., 1986b). Quantities of toxin in each fraction were measured using toxicity for EBL cells (Rutter \& Luther, 1984).

Characterization of toxin purified from recombinant $E$. coli. The homogeneity and molecular mass of the polypeptide(s) in toxin purified from the recombinants were estimated in $10 \%$ polyacrylamide SDSPAGE (Laemmli, 1970); gels were stained with silver as previously described (Chanter et al., 1986 b).

The antigenic similarity of the toxin purified from the $E$. coli clones with that purified from $P$. multocida was determined. Antiserum to toxin purified from $P$. multocida was produced in a gnotobiotic pig (Chanter et al., 1986b). The toxins were compared in an ELISA, by immunoblotting, by a cytotoxin neutralization test (Rutter \& Luther, $1984)$ and by crossed immunoelectrophoresis by the method of Moore \& Rutter (1987).

In the ELISA, microtitre plates (Falcon - Becton Dickinson) were coated overnight with $100 \mu \mathrm{l}$ of different concentrations of toxin in $50 \mathrm{~mm}$-carbonate/bicarbonate buffer $\mathrm{pH} 9 \cdot 6$. Plates were washed in isotonic PBS, pH 7.0, containing $0.03 \%$ Tween 20 (PBS/Tween) and incubated at $37^{\circ} \mathrm{C}$ for $1 \mathrm{~h}$ with serial dilutions of pig antiserum in PBS/Tween with $1 \%(w / v)$ dehydrated skimmed milk (Marvel, Cadbury). Plates were washed three times in PBS/Tween and $100 \mu l$ 1:5000 rabbit anti-swine Ig conjugated to horse radish peroxidase (Nordic Immunological Laboratories) in PBS/Tween/skimmed milk was added to each well and incubated at $37^{\circ} \mathrm{C}$ for $3 \mathrm{~h}$. Plates were washed and developed with $100 \mu 10.04 \%$ (w/v) $o$-phenylenediamine in $0.015 \%(\mathrm{w} / \mathrm{v})$ hydrogen peroxide buffered with $0.15 \mathrm{M}$-citrate/hydrogen orthophosphate, $\mathrm{nH} 5.0$ for $15 \mathrm{~min}$; the reaction was stopped with $10 \mu \mathrm{l}$ $1 \mathrm{M}$-sulphuric acid. Control wells, excluding either the antigen or the pig antiserum, were treated similarly. Absorbance at $492 \mathrm{~nm}$ was measured with a Titertec microplate reader. Control serum was from a specificpathogen-free pig aged 8 weeks.

Proteins separated by SDS-PAGE were immunoblotted by the method of Towbin et al. (1979) using a Transblot apparatus (Bio-Rad). Toxicity was assayed using EBL cells (Rutter \& Luther, 1984) and intraperitoneal injection of gnotobiotic pigs (Rutter \& Mackenzie,
1984) and was related to protein content assayed by a Coomassie dye binding method (Bio-Rad).

Treatment of pigs with recombinant toxin. Three litters of gnotobiotic pigs were used to measure toxicity following intraperitoneal inoculation of various quantities of toxin from $P$. multocida or the $E$. coli clones. The eight pigs in the first litter were divided into four groups (A-D) when they were $7 \mathrm{~d}$ old. Group A was inoculated at $1 \mu \mathrm{g}$ ( $\mathrm{kg}$ body weight $)^{-1}$ with toxin purified from $P$. multocida. Group B was inoculated with a cell lysate of recombinant TOXI with a quantity estimated to be approximately $1 \mu \mathrm{g}$ toxin $\mathrm{kg}^{-1}$, calculated from the toxicity of the lysate for EBL cells, the specific activity of purified toxin and the efficiency of purification. Group $C$ was inoculated at $1 \mu \mathrm{g} \mathrm{kg}^{-1}$ with toxin purified from recombinant TOX1 and group D was inoculated with a cell lysate of $E$. coli $\mathrm{HB} 101$ calculated to be equivalent to 10 times the dose of lysate received by group $\mathbf{B}$.

The second litter, also of eight pigs, was divided into four equal groups (A-D) at 14 days of age. Groups A and D were treated similarly to the same groups of the first litter, but group A was given $200 \mathrm{ng}$ toxin $\mathrm{kg}^{-1}$. Group $\mathrm{B}$ received toxin at $200 \mathrm{ng} \mathrm{kg}^{-1}$ purified from recombinant TOX 2 and group $\mathrm{C}$ received the same preparation but at a dose of $400 \mathrm{ng} \mathrm{kg}^{-1}$

The third litter of six pigs was divided into two groups at $14 \mathrm{~d}$ old; group A was given toxin at $440 \mathrm{ng} \mathrm{kg}^{-1}$ purified from TOX2 and group B was given a crude extract of E. coli HB101 containing pAT153.

Pigs were weighed at the start of the experiment and at post mortem $14 \mathrm{~d}$ after inoculations with toxin. All pigs in a group were fed the same amount. Damage to turbinate bones was measured by comparison of the ratio of body weight to ventral turbinate weight with that of the control group ( $D$ or $B$ ) in each case. Kidney and liver were examined for gross signs of damage. Samples of kidney, liver, bladder and ureter were fixed in neutral buffered formalin, embedded in paraffin wax, and sections cut and stained with haematoxylin/eosin. The sections were examined using a light microscope.

\section{Results}

\section{Cloning the toxin gene}

P. multocida LFB3 did not contain any plasmids; consequently, the toxin gene was isolated from a gene bank of chromosomal DNA cloned into the plasmid vector pAT153. Of the $2500 \mathrm{Ap}^{r} \mathrm{Tc}^{\mathrm{s}}$ clones with inserts, one (TOX1) was positive for toxin production. The plasmid from this clone, pAJL12, was purified and transformed into competent E. coli (BRL); 20 transformed bacteria were selected and all were toxigenic.

\section{Analysis of the toxin gene}

The plasmid pAJL12 contained a $10.7 \mathrm{~kb}$ insert. A physical map of the plasmid was constructed for 19 enzymes (Fig. 1) as follows. The sizes of the fragments generated by each enzyme were determined, and then digestions using two enzymes which each cut only once or twice were performed. It was then possible to map most of the sites by reference to the known restriction sites within the vector (Maniatis et al., 1982). The other sites were mapped using further combined digestions. 


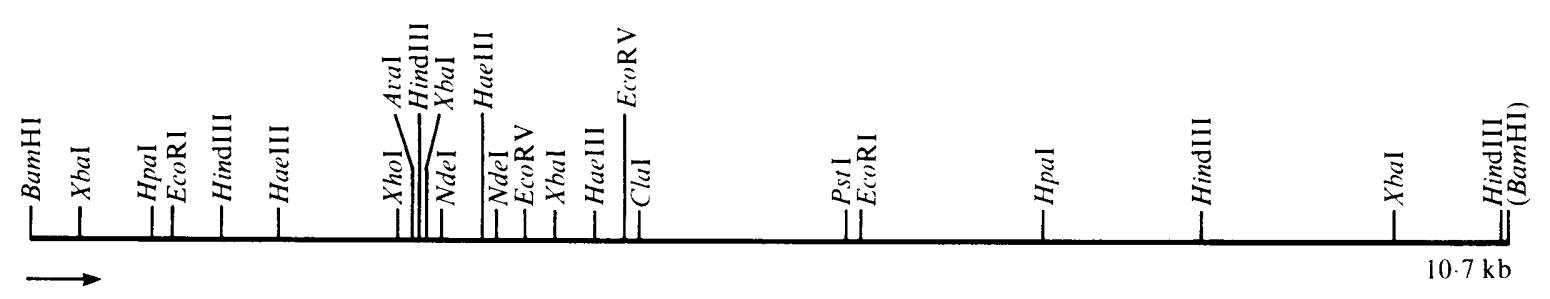

$4.9 \mathrm{~kb}$

Fig. 1. Restriction map of the inserts in the recombinant plasmids pAJL12 (top line) and pAJL13 (bottom line). The arrows indicate the direction of transcription from the tetracycline-resistance gene of pAT153. The insert in pAJL12 was not cut by $\mathrm{HpaII}, \mathrm{KpnI}, \mathrm{PvuI}$, PvuII, SalI or SstI. The BamHI site in parenthesis was lost upon ligation of the vector BamHI site to the insert SauIIIA site. Two HindIII sites between the HindIII sites at the right hand end of the insert were not mapped.

The map was unusual since the insert was not cut by HpaII or MspI, and was only cut three times by HaeIII. These three enzymes have a 4 bp recognition sequence which contains only $\mathrm{G}$ and $\mathrm{C}$ nucleotides. This suggested that the $\mathrm{G}+\mathrm{C}$ ratio of the DNA might be quite low. The enzymes DraI and SpeI, which have a 6 bp recognition sequence containing only $A$ and $T$, cut the insert at least 9 and 11 times, respectively (data not shown). Genomic DNA from P. multocida was prepared and cut with $\mathrm{HpaI}$ and HpaII, and Southern blots of the gels were probed with the $H p a I$ fragment from the insert in pAJL12. Fig. 2 shows that most of the DNA was digested by $\mathrm{HpaII}$ to fragments smaller than $4 \mathrm{~kb}$, but there were discrete bands of higher molecular mass. A band at approximately $15 \mathrm{~kb}$ hybridized to the probe. An $\mathrm{HpaI}$ fragment of approximately $6 \mathrm{~kb}$ reacted with the probe. Three other toxigenic $P$. multocida isolates produced similar fragments which also reacted with the probe.

The 2500 colonies in the clone bank were also probed with the $H p a \mathrm{I}$ fragment, and 12 other colonies hybridized. None produced toxin when tested with the EBL overlay test. Preliminary analysis of the 12 hybridizing colonies showed that they contained plasmids of different sizes.

\section{Subcloning}

It was not possible to excise the insert from pAJL12, since the BamHI cloning sites in the vector are not always regenerated after cloning SauIIIA-generated fragments. It was therefore decided to use a SauIIIA partial digestion to generate fragments of about $5 \mathrm{~kb}$, the size of the gene predicted from the size of the toxin protein. Fragments of size $5-8 \mathrm{~kb}$ were selected and ligated into pAT153. Recombinants were screened for toxicity by the EBL overlay test, and one (TOX2) contained a $5.0 \mathrm{~kb}$ insert and produced toxin. The recombinant plasmid (pAJL13) was mapped (Fig. 1); its insert was at one end of the insert in pAJL12. The

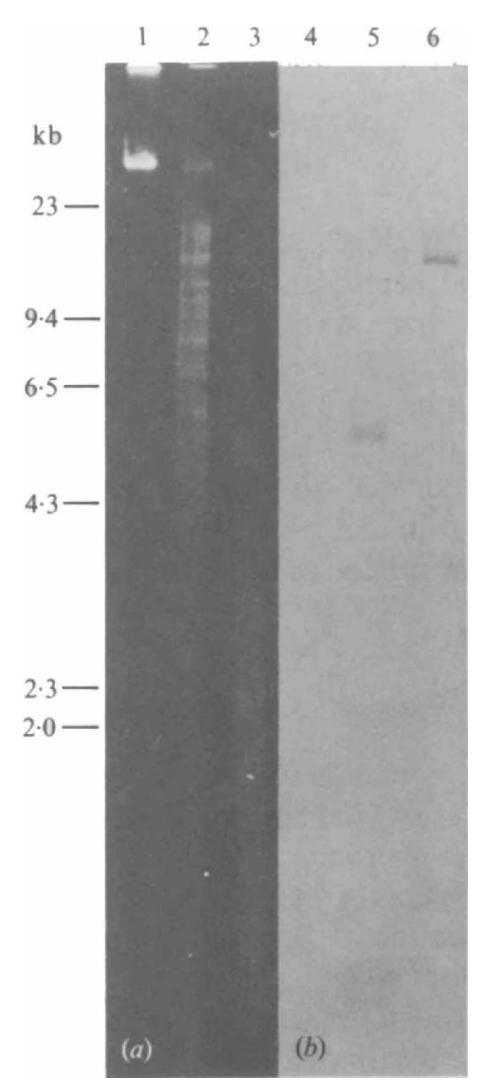

Fig. 2. (a) Agarose gel of chromosomal DNA from P. multocida LFB3: uncut (lane 1), and cut with HpaI (lane 2) or HpaII (lane 3). (b) Southern blot of the gel probed with the large HpaII fragment of pALJ12 (lanes 4-6 as lanes 1-3). 


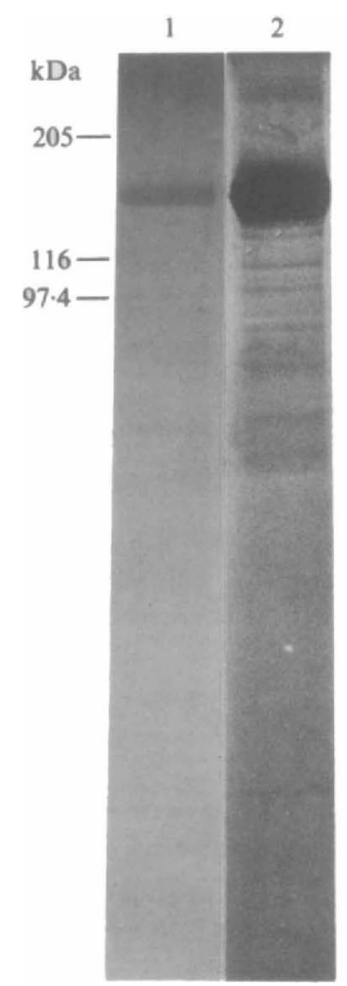

Fig. 3. SDS-PAGE of purified toxin from P. multocida LFB3 (lane 1) and $E$. coli TOX1 (lane 2).

BamHI site in pAJL12, which is probably at the end of the insert, had been transferred to pAJL13, so it was possible that there was a duplication of the vector. Mapping using EcoRI/EcoRV digestion on pAJL12 and EcoRI/Sal I on pAJL13 showed that if present this was small and less than $0 \cdot 1 \mathrm{~kb}$ (data not shown). The insert in pAJL13 was ligated to the vector in the opposite orientation to pAJL12, which implied that in at least one of the constructs the gene was transcribed from its own promoter.

\section{Purification and properties of the toxin}

The cytotoxic recombinants TOX 1 and TOX 2 produced a polypeptide of indistinguishable molecular mass $(155 \mathrm{kDa})$ to that produced by $P$. multocida. The minimum concentration of purified toxin from TOX 1 or $P$. multocida that affected EBL cells was $0.48 \mathrm{ng} \mathrm{ml}^{-1}$ and $0.5 \mathrm{ng} \mathrm{ml}^{-1}$, respectively. The yield of both cytotoxicity and toxin protein suggested that TOX1 produced approximately five times as much toxin as TOX2 and ten times as much as $P$. multocida. Like $P$. multocida both recombinants produced a faint band above the main band. There were other lower molecular mass bands (Fig. 3), but analysis of SDS-polyacrylamide gels loaded

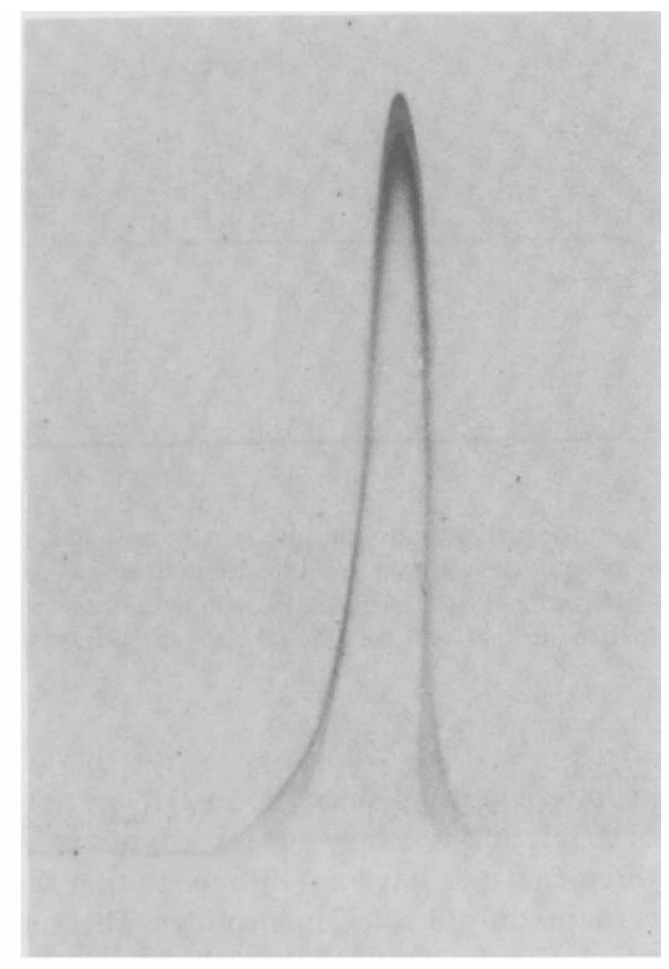

Fig. 4. Crossed immunoelectrophoresis of purified recombinant toxin reacted against gnotobiotic pig antiserum to purified toxin from $P$. multocida LFB3.

with tenfold dilutions of toxin purified from TOX1 or TOX 2 indicated that the $155 \mathrm{kDa}$ polypeptide made up $99 \%$ of the preparation.

A chequerboard titration of toxin was used to coat the microtitre plate for an ELISA and dilutions of gnotobiotic pig serum against toxin purified from $P$. multocida were made. The optimum coating concentration of antigen was $1 \mu \mathrm{g}$ per ml coating buffer for toxin from $P$. multocida or from either toxigenic recombinant. At this concentration the serum gave an identical titre of $10^{4}$ for all toxin preparations. Control serum did not react with any of the toxin preparations.

In a cytotoxin neutralization test the antiserum had a titre of $10^{3}$ with 10 cytotoxic units of toxin purified from either $P$. multocida or the recombinants.

Crossed immunoelectrophoresis of toxin from the recombinants or $P$. multocida with gnotobiotic pig antiserum to toxin purified from $P$. multocida resulted in a precipitate in the basic pattern of one peak which on closer examination was seen to be composed of several closely spaced peaks (Fig. 4), although only two of these were reproducible. The same preparations in SDSPAGE stained with silver were composed of only one major band and a fainter band with a slightly higher molecular mass. 


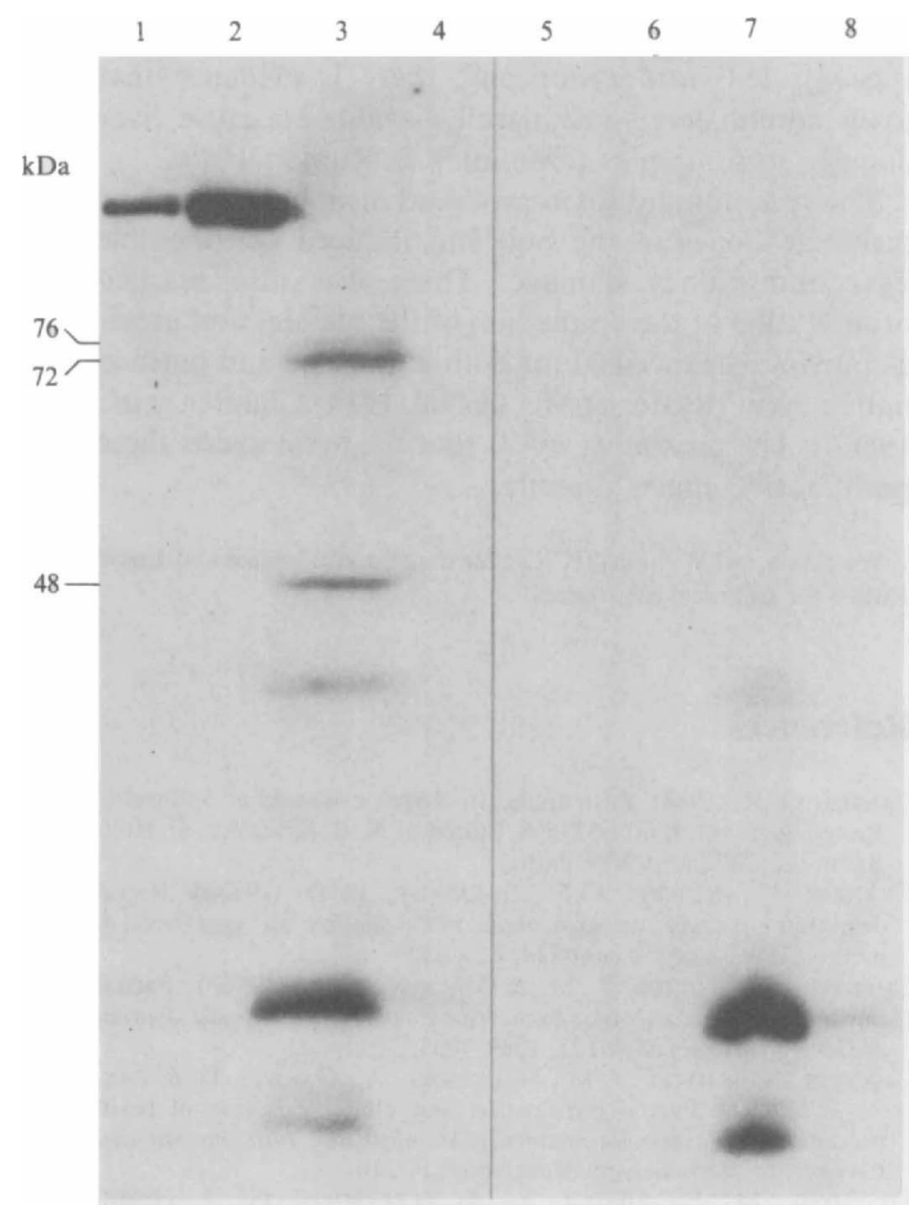

Fig. 5. Immunoblot of gnotobiotic pig serum to the purified toxin from $P$. multocida LFB3 reacted with SDS-PAGE separations of purified toxin from strain LFB3 (lane 1), purified toxin from TOX1 (lane 2), whole-cell lysate from a non-toxigenic recombinant containing part of the large $\mathrm{HpaI}$ fragment of pAJL12 (lane 3), and whole-cell lysate of $E$. coli $\mathrm{HB} 101$ containing pAT153 (lane 4). Lanes 4-8 as $1-4$ but probed only with biotinylated anti-swine $\mathrm{IgG}$ and ${ }^{125} \mathrm{I}$-labelled streptavidin.

In immunoblots, antiserum to the toxin purified from $P$. multocida reacted equally with toxin purified from $P$. multocida or the toxigenic recombinants, showing a major band of $155 \mathrm{kDa}$ (Fig. 5); minor bands were seen when the toxin had been stored for several months. Whole-cell lysates from 3 of the 12 recombinants which cross-hybridized with the $\mathrm{HpaI}$ fragment of pAJL12, but not HB101 with the vector, contained three polypeptides which reacted with antibody to toxin (Fig. 5). These had approximate molecular masses of 76,72 and $48 \mathrm{kDa}$. The same polypeptides were detected in crude extracts of the toxigenic recombinants TOX1 and TOX2. Other bands were seen if a crude extract of $E$. coli $\mathrm{HB} 101$ containing pAT 153 was used as antigen in the SDS-PAGE or if blots were probed only with biotinylated anti-swine $\operatorname{IgG}$ and ${ }^{125}$ I-labelled streptavidin, which suggested that their
Table 1. Turbinate atrophy and reduction in weight gain in pigs given recombinant toxin

\begin{tabular}{clcc}
\hline \hline $\begin{array}{c}\text { Litter/ } \\
\text { group }\end{array}$ & \multicolumn{1}{c}{ Inoculum } & $\begin{array}{c}\text { Percentage } \\
\text { turbinate } \\
\text { atrophy* }\end{array}$ & $\begin{array}{c}\text { Percentage } \\
\text { reduction in } \\
\text { weight gain* }\end{array}$ \\
\hline 2A & $200 \mathrm{ng} \mathrm{kg}^{-1}$ purified & 59 & 25 \\
& $P$. multocida toxin & 55 & 37 \\
2B & 200 $\mathrm{ng} \mathrm{kg}^{-1}$ purified & 61 & 0 \\
& TOX2 toxin & 63 & 51 \\
2C & $400 \mathrm{ng} \mathrm{kg}^{-1}$ purified & 78 & 31 \\
& TOX2 toxin & 77 & 31 \\
2D & Control & -5 & -6 \\
& & 5 & 6 \\
3A & $440 \mathrm{ng} \mathrm{kg}^{-1}$ purified & 77 & 16 \\
& TOX2 toxin & 43 & 14 \\
3B & Control & 74 & 15 \\
& & 11 & 4 \\
& & 5 & 1 \\
\hline \hline
\end{tabular}

* Calculated with respect to the mean of controls (group D for litter 1 , group B for litter 3), given a crude extract of E. coli HB101 containing pAT153.

detection was non-specific. The three polypeptides which reacted with antibody to toxin did not appear in either control.

\section{Treatment of pigs with recombinant toxin}

Crude or purified toxin from the recombinants was identical in its activity to that purified from $P$. multocida and was lethal for all but one of the pigs (found dead or killed in extremis) in the first litter. Extensive damage was caused to the liver and there was hydronephrosis of the kidneys. The surviving pig, which had been given crude toxin from the recombinant, had $59 \%$ turbinate atrophy when slaughtered $14 \mathrm{~d}$ after inoculation. Control pigs given an extract of $E$. coli $\mathrm{HB} 101$ containing pAT153 did not show signs of illness or turbinate atrophy. In litters 2 and 3, which were older and given less toxin than the first litter, all pigs survived, without signs of inappetence. There was, however, severe turbinate atrophy in pigs given toxin from $P$. multocida or the recombinant as well as a reduction in weight gain compared with control pigs (Table 1). All pigs given toxin in litter 2 showed signs of snout distortion to the left or right and all pigs given toxin purified from the recombinant had mild brachygnathia superior. The histopathological changes seen in the liver, bladder and ureters were identical to those previously found in pigs given crude toxin (Rutter \& Mackenzie, 1984). The proliferation of the transitional epithelium of the bladder and ureters was most pronounced. 


\section{Discussion}

The gene for the osteolytic toxin of $P$. multocida has been cloned and expressed in E. coli, and the protein expressed has been shown to have the same properties as the native toxin. In particular, the purified recombinant toxin reproduced severe turbinate atrophy in the pig, which is the key sign of atrophic rhinitis. The $4.9 \mathrm{~kb}$ insert in the subclone contains little other than the gene itself, since the predicted size of the toxin gene from the molecular mass of its product (Chanter et al., 1986b) and the molar ratios of its composite amino acids (Nakai et al., 1984) would be $4.8 \mathrm{~kb}$. This shows that the $P$. multocida toxin is sufficient to explain the pathology observed and any mechanism directly involved must be connected to the whole toxin molecule or fragments generated from it.

Restriction data suggested that the insert encoding the toxin was very A + T rich, in contrast to the rest of the $P$. multocida genome (Carter, 1984). It was also of interest that the gene was on a HpaII fragment of about $15 \mathrm{~kb}$. This suggested that a simple method of cloning this gene or variants of it would be to extract the large HpaII fragment and insert it into a suitable vector. The significance of the abnormal base ratio is not clear, but could perhaps reflect a difference between the toxin gene and its flanking sequences and the remaining $P$. multocida genome. The gene was expressed at a high level in $E$. coli, and produced about $15 \%$ of the total protein in one of the recombinants. The gene was not found in nontoxigenic $P$. multocida (unpublished observations).

The significance of additional polypeptides produced by the toxigenic recombinants, and the non-toxigenic recombinants containing part of the gene, is unknown. These polypeptides are not found in toxigenic $P$. multocida either in crude extracts or in purified toxin prepared by either affinity chromatography (Chanter $e t$ $a l ., 1986 c$ ) or immunoabsorbent chromatography using a monoclonal antibody (Foged, 1988). Since the insert in pAJL13 was only just large enough to encode the whole toxin, the additional polypeptides antigenically related to the toxin must have been encoded by the toxin gene. This suggests that there are either initiation or stop signals within the gene that are not utilized by $P$. multocida but which are recognized by the $E$. coli transcription system. Alternatively there might be posttranslational breakdown of the protein in $E$. coli.

The toxin purified from the recombinant TOX2 was able to reduce weight gain compared with controls without affecting food consumption. Therefore the association of atrophic rhinitis with poor economic performance might, like turbinate atrophy, have a molecular basis ultimately dependent on the toxin of $P$. multocida. For such an effect in the natural disease the toxin would have to gain entry to the circulation from the nasal cavity. Although in these experiments the toxin was injected intraperitoneally, there is evidence that toxin administered intranasally is able to cause liver damage in some pigs (Dominick \& Rimler, 1986).

The recombinant toxin produced atrophy of the nasal turbinate bones of the pig, and induced considerable liver and kidney damage. There was also marked proliferation of the epithelium of the bladder and ureter as previously described for both unpurified and purified native toxin (Rutter \& Mackenzie, 1984; Chanter et al., $1986 b$ ). The possibility exists that the toxin exerts these proliferative effects directly.

We thank Jeff Williams (ICRF) for much useful advice and Ingrid Aitken for technical assistance.

\section{References}

Carter, G. R. (1984). Pasteurella. In Bergey's Manual of Systematic Bacteriology, vol. 1, pp. 552-558. Edited by N. R. Krieg \& J. G. Holt. Baltimore: Williams \& Wilkins.

Chanter, N., Rutter, J. M. \& Luther, P. D. (1986a). Rapid detection of toxigenic Pasteurella multocida by an agar overlay method. Veterinary Record 119, 629-630.

Chanter, N., Rutter, J. M. \& Mackenzie, A. (1986b). Partial purification of an osteolytic toxin from Pasteurella multocida. Journal of General Microbiology 132, 1089-1097.

Chanter, N., Rutter, J. M., Mackenzie, A., Garwes, D. \& Lax, A. J. $(1986 c)$. Partial purification and characterisation of toxin produced by Pasteurella multocida. In Abstracts, 14th International Congress of Microbiology, Manchester, p. 210.

De Jong, M. F., OeI, J. L. \& Tetenburg, G. J. (1980). AR-pathogenicity-tests for Pasteurella multocida isolates. In Proceedings of the 6th International Pig Veterinary Society Congress, p. 211. Edited by N. C. Nielsen, P. Hogh \& N. Bille.

Dominick, M. A. \& Rimler, R. B. (1986). Turbinate atrophy in gnotobiotic pigs intranasally inoculated with protein toxin isolated from type D Pasteurella multocida. American Journal of Veterinary Research 47, 1532-1536.

FoGED, N. T. (1988). Quantitation and purification of the Pasteurella multocida toxin by using monoclonal antibodies. Infection and Immunity 56, 1901-1906.

Foged, N. T., Elling, F. \& Pederson, K. B. (1986). Isolation and characterization of a toxin from Pasteurella multocida. In Proceedings of the 9th International Pig Veterinary Society Congress, p. 231.

IL'INA, Z. M. \& ZASUKHIN, M. I. (1975). Role of pasteurella toxins in the pathogenesis of atrophic rhinitis. Sbornik Nauchynkh Rabot, Sibirskogo Zonal'nogo Nauchno-Issledovatel'skogo Veterinarnogo Instituta 25, 76-86.

IsH-Horowitz, D. \& BURKE, J. F. (1981). Rapid and efficient cosmid cloning. Nucleic Acids Research 9, 2989-2998.

JONES, P. W. \& MATTHEWS, P. R. J. (1975). Examination of slurry from cattle for pathogenic bacteria. Journal of Hygiene 74, 57-64.

Kamp, E. M., Van der Heijdan, P. J. \& Tetenburg, B. J. (1987). Purification of a heat labile dermonecrotic toxin from culture fluid of Pasteurella multocida. Veterinary Microbiology 13, 235-248.

LAEMMLI, U. K. (1970). Cleavage of structural proteins during the assembly of the head of bacteriophage T4. Nature, London 227, 680-685.

Maniatis, T., Fritsch, E. F. \& SAmbrook, J. (1982). Molecular Cloning: a Laboratory Manual. Cold Spring Harbor, NY: Cold Spring Harbor Laboratory.

MoOre, L. J. \& RutTer, J. M. (1987). Antigenic analysis of fimbrial proteins from Moraxella bovis. Journal of Clinical Microbiology 25, 2063-2070. 
Nakai, T., Sawata, A., Tsuji, M., Samejima, Y. \& Kume, K. (1984). Purification of dermonecrotic toxin from a sonic extract of Pasteurella multocida SP-72 serotype D. Infection and Immunity 46, 429-434.

Rimler, B. R. \& Brogden, K. A. (1986). Pasteurella multocida isolated from rabbits and swine: serologic types and toxin production. American Journal of Veterinary Research 47, 730-737.

RUTTER, J. M. (1983). Virulence of Pasteurella multocida in atrophic rhinitis of gnotobiotic pigs infected with Bordetella bronchiseptica. Research in Veterinary Science 34, 287-295.

RutTer, J. M. (1985). Atrophic rhinitis of swine. In Advances in Veterinary and Comparative Medicine, vol. 29, pp. 239-279. Edited by C. E. Cornelius \& C. F. Simpson. Orlando, Florida: Academic Press.

RutTer, J. M. \& LutheR, P. D. (1984). Cell culture assay for toxigenic
Pasteurella multocida from atrophic rhinitis of pigs. Veterinary Record 114, 393-396.

Rutter, J. M. \& Mackenzie, A. (1984). Pathogenesis of atrophic rhinitis in pigs: a new perspective. Veterinary Record 114, 89-90.

SaIto, H. \& MiURA, K. (1963). Preparation of transforming deoxyribonucleic acid by phenol treatment. Biochimica et Biophysica Acta 72, 619-629.

SWITZER, W. P. \& FARRINGTon, D. O. (1975). Infectious atrophic rhinitis. In Diseases of Swine, 4th edn, pp. 687-711. Edited by H. W. Dunne \& A. D. Leman. Ames: Iowa State University Press.

Towbin, H., Staehelin, T. \& Gordon, J. (1979). Electrophoretic transfer of proteins from polyacrylamide gels to nitrocellulose sheets: procedure and some applications. Proceedings of the National Academy of Sciences of the United States of America 76, 4350-4354. 